\title{
ASPECTOS TECNOLÓGICOS DA “TINY HOUSE” E SUA REGULAMENTAÇÃO NO BRASIL FRENTE À SUSTENTABILIDADE SOCIOAMBIENTAL
}

\author{
TECHNOLOGICAL ASPECTS OF THE “TINY HOUSE” AND ITS \\ REGULATION IN BRAZIL IN FRONT OF SOCIO- \\ ENVIRONMENTAL SUSTAINABILITY
}

\section{Patricia Etsuko Issonaga* Deise Marcelino da Silva**}

* Mestranda em Direito, Sociedade e Tecnologias pela Faculdades Londrina (2020). Pós-graduada em Direito Constitucional Contemporâneo pelo Instituto de Direito Constitucional e Cidadania IDCC/Londrina (2016). Graduada em Direito pela UNIFIL (2014). VicePresidente da Comissão do Núcleo da Justiça Estadual da OAB de Londrina/PR. Advogada.

E-mail:

patriciaissonaga@gmail.com

** Doutora em Direito Ambiental Internacional pela UNISANTOS (2017). Mestre em Direitos da Personalidade pelo Centro Universitário de Maringá/PR (2010). Especialização em Docência no Ensino Superior. Pós-graduada em Direito Ambiental e Sustentabilidade pelo Instituto de Direito Constitucional e Cidadania - IDCC/Londrina (2012). Membro da Comissão de Meio Ambiente da OAB de Maringá/PR. Professora. Advogada.

E-mail:

deise.marcelino@hotmail.com
Como citar ISSONAGA, Patrícia Etsuko; SILVA, Deise Marcelino da. O novo Direito Constitucional de proteção ao consumidor: políticas públicas e judiciário. Revista do Instituto de Direito Constitucional e Cidadania - IDCC, Londrina, v. 5, n. 2, e014, ago/dez, 2020. ISSN: 2596-0075. DOI: 10.48159/revistadoidcc.v5n2.issonaga.silva

Resumo: O artigo analisa os aspectos conceituais, tecnológicos e sociais da implementação da tiny house no Brasil. Parte-se da ideia segundo a qual a casa minúscula é uma inovação que pode ser colocada à disposição como opção sustentável de habitação nos municípios brasileiros. Pretende-se ressaltar as complexidades e interdependências da habitação em tiny house a partir da análise da legislação vigente. Trata-se de pesquisa bibliográfica relevante frente à efetividade dos direitos fundamentais consubstanciados no direito à moradia e ao meio ambiente ecologicamente equilibrado. Ademais, o estudo leva em consideração o princípio da solidariedade e do desenvolvimento sustentável como paradigma para os processos de inovação e tecnologia. O resultado obtido aponta que a tiny house compreendida como habitação sustentável é um importante instrumento para valorização do direito à propriedade, mediante o desafio da necessidade de adequação das normas do ordenamento jurídico brasileiro.

Palavras-chave: Tiny house; Sustentabilidade; Legislação; Tecnologias.

Abstract: The article analyzes the conceptual, technological and social aspects of the implementation of the "tiny house" in Brazil. It starts with the idea that the tiny house is an innovation that can be made available as a sustainable housing option in Brazilian municipalities. It is intended to highlight the complexities and interdependencies of "tiny house" housing from the analysis of current legislation. This is a relevant bibliographic research in view of the effectiveness of fundamental rights embodied in the right to housing and the ecologically balanced environment. In addition, the study takes into account the principle of solidarity and sustainable development as a paradigm for innovation and technology processes. The result obtained points out that sustainable housing is an important instrument for valuing property law, through the challenge of the need to adapt the rules of the Brazilian legal system.

Keywords: Tiny house; Sustainability; Legislation; Technologies. 


\section{INTRODUÇÃO}

Tiny house significa casa minúscula. Sua montagem pode ser sobre rodas ou em base fixa. O presente trabalho pretende discutir a dificuldade de implementação da tiny house no Brasil diante da escassez de legislação específica para esse modelo de habitação. A implementação da tiny house sugere análise sob três aspectos: o modo minimalista de ser que se coaduna com o desenvolvimento sustentável e a proteção ambiental, a opção de moradia frente ao déficit habitacional no Brasil e a implementação de tecnologias ambientais na sua construção. Tais abordagens foram levantadas no decorrer dos capítulos dessa pesquisa, estabelecendo a interface com o Direito.

O tema permeia várias áreas do conhecimento, como a engenharia civil, a inovação tecnológica e a sociologia. Entretanto, importante constar que se trata de um estudo jurídico com enfoque, principalmente, nas leis ambientais e urbanísticas que disciplinam a implementação da tiny house no Brasil. Ademais, o texto leva em consideração os direitos fundamentais à moradia e ao meio ambiente ecologicamente equilibrado.

Para tanto, o artigo apresenta os aspectos conceituais de tiny house e as peculiaridades do estilo de vida em casa com estrutura minúscula. Optou-se pela metodologia objetiva em pesquisa exploratória para a abordagem do tema, em busca da efetividade do direito à moradia e da necessidade de respeito ao equilíbrio ambiental; apontando usos nocivos ao meio ambiente, e oferecendo opções sustentáveis que, a um só tempo, respeitem o direito de propriedade e a legislação ambiental, o que viabilizaria a prática sustentável de moradia popular no modelo tiny house.

O procedimento da pesquisa bibliográfica foi elaborado com referência a livros e artigos de autores brasileiros e estrangeiros, legislações, informações em sites oficiais, discorrendo sobre o tema e a relação do direito à propriedade e do desenvolvimento sustentável como paradigma para os processos de inovação e tecnologia ambiental pelo direito à moradia, priorizando maior qualidade de vida.

O principal objetivo do presente artigo é salientar a importância da opção de moradia em tiny house no Brasil, apontando seus tipos e suas principais características e viabilidades de inovação, com desígnio no contexto social brasileiro. Utilizou-se a metodologia de natureza aplicada, a fim de sugerir soluções e atitudes práticas para que o imóvel atenda a sua função 
social, propondo que a tiny house seja uma opção sustentável de moradia, amoldável às normas jurídicas brasileiras.

O texto está estruturado em quatro partes. A primeira apresenta o conceito de tiny house e as ideias envoltas à expressão. A segunda parte expõe as tecnologias sustentáveis inerentes à implementação da tiny house, com vistas à proteção ambiental. Os aspectos sociais que envolvem a moradia em "tiny house” foram abordados na terceira parte. Na última parte, apresentou-se um caso concreto de construção de condomínio de tiny house no Município de Curitiba, Estado do Paraná.

Optou-se pela metodologia objetiva em pesquisa exploratória para a abordagem do tema, em busca da efetividade do direito à moradia e da necessidade de respeito ao equilíbrio ambiental, transformando os comportamentos nocivos ao meio ambiente em hábitos e consumismos sustentáveis e eficácia do exercício do direito de propriedade.

\section{TINY HOUSE: APROXIMAÇÃO AO TEMA}

A palavra "tiny”1 é um adjetivo de origem inglesa que significa minúsculo, pequeno, ínfimo. Não há uma conceituação estrita e consolidada da habitação para a casa minúscula com

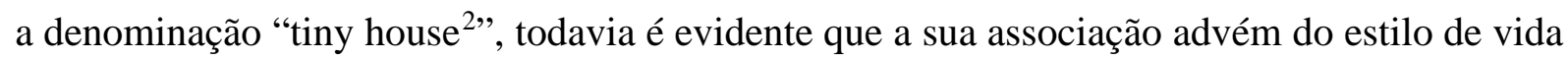
minimalista $^{3}$ (FERREIRA, 2010) que é a simplificação com base de expressão simples, eliminando os excessos, em busca de soluções na preservação ambiental, priorizando apenas o que é essencial.

Construídas em bases fixas ou sobre rodas, a tiny house recebe diferentes tratamentos na legislação de cada país. No Brasil, a tiny house sobre rodas, segundo a regulamentação do Conselho Nacional de Trânsito pode ser construída para fins de alojamento, escritório, comércio ou finalidades análogas, assim como os requisitos e normas para circulação e fiscalização dos veículos modificados ou transformados. A montagem também pode ser construída sobre fundação fixa utilizando as regras e os mesmos parâmetros das construções de imóveis convencionais.

1 CAMBRIGDE DICTIONARY. Tiny. Disponível em: <https://dictionary.cambridge.org/pt/dicionario/inglesportugues/tiny>. Acesso em: 01 Nov. 2020.

2 CAMBRIGDE DICTIONARY. House. Disponível em: https://dictionary.cambridge.org/pt/dicionario/ingles-portugues/house>. Acesso em: 01 Nov. 2020.

3 FERreirA, Aurélio Buarque de Holanda. Dicionário Aurélio da Língua Portuguesa. Minimalista. $5^{\mathrm{a}}$ Edição. Curitiba: Positivo, 2010. 


\section{ASPECTOS TECNOLÓGICOS DA “TINY HOUSE” E SUA REGULAMENTAÇÃO NO BRASIL FRENTE À SUSTENTABILIDADE SOCIOAMBIENTAL}

A previsão legal para a tiny house em construção sobre rodas é restrita aos parâmetros determinados pela Lei n 9.503/19974 (BRASIL, 1997) do Código de Trânsito Brasileiro e em obediência às diretrizes da Política Nacional de Trânsito, Decreto $n^{\circ} 4.711 / 2003^{5}$ (BRASIL, 2003) sobre a coordenação do Sistema Nacional de Trânsito e Resolução n 743/2018 ${ }^{6}$ (BRASIL, 2018) do Conselho Nacional de Trânsito que determinam os requisitos técnicos para modificação ou transformação de veículos.

Pela ausência de legislação específica sobre o tema, a tiny house em fundação fixa deve adaptar-se à vigência das normas municipais locais, segundo estabelecido na Lei $\mathrm{n}^{\circ}$ 4.591/19647 (BRASIL, 1964) que dispõe sobre os condomínios e as edificações imobiliárias, na conformidade da Lei $n^{\circ} 6.015 / 1973^{8}$ (BRASIL, 1973), a qual trata dos registros públicos, ainda na Lei ${ }^{\circ}$ 6.766/1979 ${ }^{9}$ (BRASIL, 1979) sobre o parcelamento do solo urbano; bem como na Lei $n^{\circ} 7.433 / 1985^{10}$ (BRASIL, 1985) e no Decreto $n^{\circ}$ 93.240/1986 ${ }^{11}$ (BRASIL, 1986), os quais dispõem sobre os procedimentos das lavraturas de escrituras públicas.

Ainda que por definição, a tiny house seja casa minúscula, seu conceito não se resume à ideia de habitação popular. A moradia em tiny house pode se enquadrar em diversos conceitos, segundo a conceituação de $\mathrm{ABIKO}^{12}$ (1995), no mesmo entendimento, a tiny house construída sobre fundação fixa:

\footnotetext{
Habitação popular é um termo genérico que define uma determinada solução de moradia voltada para a população de baixa renda. Além desta denominação genérica pode-se encontrar outras como: habitação sub-normal, habitação de interesse social ou habitação social, habitação de baixo custo e habitação para população de baixa renda.
}

\footnotetext{
4 BRASIL. Código de Trânsito Brasileiro (1997). Disponível em: <http://www.planalto.gov.br/ccivil_03/leis/L9503Compilado.htm>. Acesso em: 01 Nov. 2020.

5 BRASIL. Sistema Nacional de Trânsito (2003). Disponível em: <http://www.planalto.gov.br/ccivil_03/decreto/2003/D4711.htm>. Acesso em: 01 Nov. 2020.

6 BRASIL. Resolução $\mathbf{n}^{\circ} \mathbf{7 4 3 / 2 0 1 8}$ do Conselho Nacional de Trânsito (2018). Disponível em: <https:/www.in.gov.br/materia/-/asset_publisher/Kujrw0TZC2Mb/content/id/51523850/do1-2018-11-23resolucao-n-743-de-12-de-novembro-de-2018-51523534>. Acesso em: 01 Nov. 2020.
}

7 BRASIL. Condomínio em edificações e as incorporações imobiliárias (1964). Disponível em: <http://www.planalto.gov.br/ccivil_03/leis/l4591.htm>. Acesso em: 01 Nov. 2020.

8 BRASIL. Registros Públicos (1973). Disponível em: http://www.planalto.gov.br/CCivil_03/leis/L6015consolidado.htm>. Acesso em: 01 Nov. 2020.

9 BRASIL. Parcelamento do Solo Urbano (1979). Disponível em: < http://www.planalto.gov.br/ccivil_03/LEIS/L6766.htm>. Acesso em: 01 Nov. 2020.

10 BRASIL. Lavratura de Escrituras Públicas (1985). Disponível em: < http://www.planalto.gov.br/ccivil_03/leis/l7433.htm>. Acesso em: 01 Nov. 2020.

11 BRASIL. Requisitos para Lavraturas de Escrituras Públicas (1986). Disponível em: <http://www.planalto.gov.br/ccivil_03/decreto/Antigos/D93240.htm>. Acesso em: 01 Nov. 2020.

12 ABIKO, Alex Kenya. Introdução à gestão habitacional. São Paulo, EPUSP. Texto técnico da Escola Politécnica da USP, Departamento de Engenharia de Construção Civil, TT/PCC/12. 1995. 
Habitação sub-normal é definida pela Prefeitura Municipal de São Paulo como aquela que não oferece as condições mínimas de segurança, durabilidade, tamanho, salubridade e não permite a seus moradores o atendimento de atividades como membro de grupos primários; estas condições referem-se tanto aos aspectos da construção (dimensionamento, número e disposição dos cômodos, material, estrutura, etc.) quanto à carência e localização de sanitários, ausência de água encanada, de ligação às redes de esgoto e de energia elétrica.

Habitação de interesse social ou habitação social é um termo usado pelo extinto BNH envolvendo os seus programas para faixas de menor renda. Este termo continua a ser utilizado por várias instituições e agências na área habitacional.

Habitação de baixo custo (low-cost housing) é um termo utilizado para designar habitação barata sem que isto signifique necessariamente habitação para população de baixa renda.

Habitação para população de baixa renda (housing for lowincome people) é um termo mais adequado que o anterior, tendo a mesma conotação que habitação social; estes termos trazem, no entanto a necessidade de se definir a renda máxima das famílias e indivíduos situados nesta faixa de atendimento social.

A habitação popular não deve ser entendida meramente como um produto e sim como um processo, com uma dimensão física, mas também como resultado de um processo complexo de produção com determinantes políticos, sociais, econômicos, jurídicos, ecológicos, tecnológicos. Este entendimento é fundamental se quisermos perseguir a solução do problema habitacional com todas as suas dificuldades e condições de contorno (ABIKO, 1995).

O direito de propriedade ${ }^{13}$ encoraja os indivíduos a introduzir melhorias em seus bens imóveis, pois permitem que os proprietários colham os benefícios dessas melhorias. Trata-se de um arranjo social criado para fins sociais: tem um efeito positivo perceptível sobre o estoque de bens imóveis e de capital do país ${ }^{14}$ (HOLMES e SUSTEIN, 2019).

Tal arranjo social, contudo, se depara com a ausência de moradia decente, que não consiste no fato de determinada classe social viver em casas mal construídas, apinhadas e/ou insalubres, mas caracterizada pelas más condições de habitação, consequência da repentina afluência da população às grandes cidades. Com a expansão das grandes cidades modernas, o solo é valorizado nas áreas urbanas de modo que a habitação e a indústria imobiliária apenas excepcionalmente priorizam o atendimento da classe de menor condição financeira, colaborando para o desequilíbrio social ${ }^{15}$ (ENGELS, 2013).

Assim, o desequilíbrio social se reflete na dificuldade de regularização dos imóveis no Brasil. É um longo, caro e burocrático processo administrativo no Município que o imóvel

13 BRASIL. Constituição da República Federativa do Brasil (1988). Artigo 5, Inciso XXII. Disponível em: <http://www.planalto.gov.br/ccivil_03/constituicao/constituicao.htm>. Acesso em: 01 Nov. 2020.

14 HOLMES, Stephen. SUNSTEIN, Cass R. O Custo dos Direitos: Porque a liberdade depende dos impostos. Tradução: Marcelo Brandão Cipolla. 1 ${ }^{a}$ Edição. São Paulo: WMF Martins Fontes, 2019, p.93-94.

15 ENGELS, Friedrich. A Questão da Habitação. São João del Rei: Estudos Vermelhos, 2013. 


\section{ASPECTOS TECNOLÓGICOS DA “TINY HOUSE” E SUA REGULAMENTAÇÃO NO BRASIL FRENTE À SUSTENTABILIDADE SOCIOAMBIENTAL}

estiver estabelecido, conforme as disposições legais e normas vigentes, conforme já citado e dos quais se podem destacar alguns elementos:

01) apresentação do contrato de compra e venda do terreno ou do imóvel já construído, comprovando-se a aquisição do bem;

02) emissão da escritura pública para validar a negociação do imóvel, lavrado no Cartório de Notas local;

03) emissão da matrícula para individualizar o imóvel, no Cartório de Registro de Imóveis local;

04) projeto arquitetônico aprovado pela Prefeitura do Município;

05) obtenção do alvará de construção, junto a Prefeitura do Município;

06) obtenção do alvará de regularização, junto a Prefeitura do Município;

07) obtenção do auto de conclusão de obra, popularmente conhecido por "habite-se”, garantindo a segurança, aprovado pelas normas da Prefeitura do Município mediante vistoria técnica;

08) atualização da averbação do imóvel sempre que houver qualquer tipo de alteração, seja na construção ou por alteração do estado civil.

A habitação em tiny house não se encaixa nesse contexto jurídico vigente. $\mathrm{O}$ desenvolvimento das subjetividades de consumo em torno da escolha em habitação na tiny house é inerente ao estilo do morador. Este desenvolvimento das subjetividades ocorre na visão analítica do próprio morador que decide ser governado pela necessidade de restringir e sacrificar ou em determina-se como governador de sua decisão, que escolhe como e quando consumir, dentro de parâmetros restritos ${ }^{16}$ (CARRAS, 2018).

\footnotetext{
Regra geral, quem diz que não quer uma "casa tecnológica” não tem noção do que está falando. Esquece-se de que toda casa é tecnológica. Ou está apenas dizendo que, às tecnologias domésticas contemporâneas, prefere tecnologias domésticas de tempos transatos. O problema, portanto, não é a tecnologia em si. Uma chaleira é tão tecnológica quanto um computador, ou quanto os neomuxarabis de Jean Nouvel no Instituto do Mundo Árabe, em Paris - persianas que abrem e fecham automaticamente, a depender da intensidade da luz externa. A história tecnológica da humanidade tem, entre suas referências mais remotas, uma forquilha ou espeto para extrair tubérculos do chão, em pequenas expedições de coleta alimentar. Quem hoje estreia, em sua casa, devices domésticos recentíssimos, pretendendo maravilhar visitas, nem sempre consegue imaginar a surpresa e a transformação causadas pelo aparecimento do garfo de mesa, séculos atrás (...) (RISÉRIO, 2019) ${ }^{17}$.
}

16 CARRAS, Megan Elizabeth. “Tiny House, Big Impact?”: An investigation into the 'rise’ of the Tiny Home Lifestyle (THL) in the United States. Reino Unido (Escócia): University of St Andrews, 2018.

17 RISÉRIO, Antonio. A Casa no Brasil. $1^{a}$ Edição. Rio de Janeiro: Topbooks, 2019, p.328-329. 
Morar em tiny house significa vivenciar as opções tecnológicas e sociais, não apenas pelo viés jurídico do direito de propriedade ${ }^{18}$, mas perante o potencial de transformação dos comportamentos nocivos ao meio ambiente em bons hábitos, com práticas de consumo sustentáveis, dentre as quais se destacam: Gerador de fonte de energia elétrica e fonte da geração de calor por radiação solar ${ }^{19}$; Gerador por biodigestor e uso de biogás ${ }^{20}$; Uso de banheiro seco de compostagem ${ }^{21}$; Armazenamento e aproveitamento de água da chuva ${ }^{22}$; Melhor aproveitamento do espaço e móveis multifuncionais; Aquisição de eletrodomésticos e eletroeletrônicos, no consumo responsável e essencial ${ }^{23}$.

\section{TECNOLOGIAS SUSTENTÁVEIS NA IMPLEMENTAÇÃO DA TINY HOUSE}

Tecnologia é uma palavra que indica algo tangível, bem como intangível. A tecnologia intangível pode ser compreendida como o conjunto de saberes, técnicas, experiências e expertises aplicadas na criação ou melhoramento de produtos, processos ou serviços. $\mathrm{O}$ resultado dessa aplicação, ou seja, o produto tecnológico é o objeto tangível da tecnologia. Assim, a expressão

"tecnologia" pode se referir a um corpo de conhecimento necessário para gerar novas regras para o projeto, construção e aplicação de possibilidades técnicas para diferentes tipos de problemas (como, por exemplo, o controle da poluição ambiental) ${ }^{24}$.

Considera-se, no âmbito desse trabalho, a tiny house como um produto tecnológico que poderá ser usada diretamente na solução de problemas ambientais, pois a construção desse modelo de casa implica menos recursos naturais e mais tecnologias sustentáveis.

18 BRASIL. Constituição da República Federativa do Brasil (1988). Artigo 5² Inciso XXII. Disponível em: <http://www.planalto.gov.br/ccivil_03/constituicao/constituicao.htm>. Acesso em: 01 Nov. 2020.

19 BNDES. Banco Nacional do Desenvolvimento (2018). Disponível em: <https://www.bndes.gov.br/wps/portal/site/home/conhecimento/noticias/noticia/energia-solar>. Acesso em: 01 Nov. 2020.

20 Informação divulgada pelo Ministério de Minas e Energia: <http://www.mme.gov.br/todas-as-noticias//asset_publisher/pdAS9IcdBICN/content/governo-federal-inaugura-uma-das-maiores-plantas-de-biogas-nomundo-para-geracao-de-energia-eletrica-sustentavel>. Acesso em: 01 Nov. 2020.

21 JEnKINS, Joseph C. The Humanure Handbook. A Guide to Composting Human Manure. Third Edition.. USA: Chelsea Green, 2005.

22 ABNT. ABNT NBR 15527 (2007). Aproveitamento de água da chuva. Disponível em: <https://www.abntcatalogo.com.br/curs.aspx?ID=34>. Acesso em: 01 Nov. 2020.

23 IBGE. Habitação. Instituto Brasileiro de Geografia e Estatística (2020). Disponível em: <https://brasilemsintese.ibge.gov.br/habitacao.html>. Acesso em: 01 Nov. 2020.

24 ONU. O impacto da tecnologia nos direitos humanos: estudos de caso globais, United Nations University Press. 1993, p. 32) 


\section{ASPECTOS TECNOLÓGICOS DA “TINY HOUSE” E SUA REGULAMENTAÇÃO NO BRASIL FRENTE À SUSTENTABILIDADE SOCIOAMBIENTAL}

Entende-se por tecnologia sustentável aquela capaz de manter a ordem dos elementos social, econômico e ambiental - em harmonia. A tecnologia voltada para a perenidade e resiliência dos recursos ambientais pode ser chamada de tecnologia sustentável. As tecnologias sustentáveis, também conhecidas como tecnologias verdes ou ambientais, tem potencial para reduzir as externalidades negativas provocadas pela interferência antrópica no ambiente. Ademais

As tecnologias ambientais fornecem soluções para diminuir os influxos de substâncias, reduzir o consumo de energia e as emissões, reaproveitar os subprodutos e minimizar os problemas da eliminação de resíduos. Melhoram a ecoeficiência, ou seja, permitem "fazer mais com menos", apoiam a aplicação de sistemas de gestão ambiental e tornam os processos produtivos mais ecológicos ${ }^{25}$.

A construção civil é uma atividade que gera resíduos e subprodutos em grande monta. Trata-se de um problema ambiental a ser enfrentado pela sociedade com vistas à higidez ambiental. Como medida de mitigação aos problemas ambientais causados pela construção de casas e edifícios, imperioso lançar mão das tecnologias sustentáveis disponíveis. Entre as tecnologias sustentáveis aplicadas nesse contexto, elegeu-se aquelas implementadas na construção de tiny house.

As tecnologias sustentáveis aplicadas à implementação da tiny house são aquelas vinculadas, principalmente, à geração de energia.

Segundo publicação do Banco Nacional do Desenvolvimento26 (BNDES, 2018) como fonte primária de energia, a radiação solar tem papel de destaque na transformação de economias baseadas em combustíveis fósseis e em economias de baixo carbono, imprescindível para amenizar os efeitos adversos das mudanças climáticas, além de atender aos compromissos das nações e do Brasil estabelecidos no Acordo de Paris ${ }^{27}$ (BRASIL, 2016).

O gerador de gás por biodigestor é um compartimento fechado e o biogás é resultado da degradação da matéria orgânica deste compartimento, fonte de energia renovável e bem mais

25 AGENCIA EUROPEIA DO AMBIENTE. Sobre tecnologia ambiental. Disponível em: <https://www.eea.europa.eu/pt/themes/technology/about>. Acesso em: 01 Dez. 2020.

26 BNDES. Banco Nacional do Desenvolvimento (2018). Disponível em: <https://www.bndes.gov.br/wps/portal/site/home/conhecimento/noticias/noticia/energia-solar>.

27 BRASIL. Acordo de Paris (2016). Ministério do Meio Ambiente.Disponível em: <https://www.mma.gov.br/clima/convencao-das-nacoes-unidas/acordo-de-paris.html>. Acesso em: 01.Nov. 2020 
limpa que o gás natural. O Ministério de Minas e Energia ${ }^{28}$ enaltece o uso de biogás no Brasil por tratar-se de energia elétrica sustentável.

O uso do produto da biomassa, a matéria orgânica que gera o biogás composta por lixos orgânicos (resíduos de fezes, urina, lixo doméstico, resíduos industriais e restos de produção de origem vegetal e animal) proporciona a economia de água, redução na emissão de gases e resíduos poluentes, como também a minimização dos impactos ambientais.

O biometano é obtido a partir do refinamento e processamento do biogás, sendo necessária a sua conversão e purificação, resultando em combustível com elevado teor do gás metano, comprimido por meio de gasodutos de forma similar ao gás natural, regulamentado

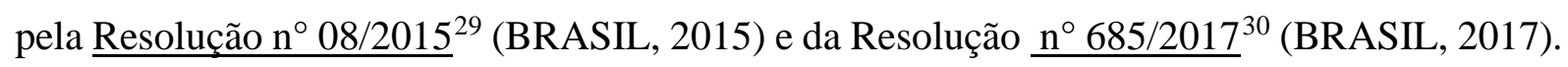

O banheiro seco de compostagem é um sistema de saneamento básico e ecológico, mais sustentável da atualidade. Neste sistema, os excrementos (fezes e urina) são depositados e cobertos por materiais de cobertura seca (serragem de madeira) formando a mistura que promove o fenômeno denominado compostagem. Os microrganismos naturalmente presentes se proliferam, digerindo a matéria orgânica transformando em húmus, que é um rico fertilizante orgânico agrícola utilizado para nutrir o solo, sem riscos à saúde humana ${ }^{31}$ (JENKINS, 2005).

O banheiro seco de compostagem traz grandes vantagens para o morador da tiny house porque não necessita do uso de água, não gera esgotos ou qualquer poluição que agride o meio ambiente, além de resultar em fertilizante que permite a devolução dos nutrientes ao solo para a produção agrícola e completa reciclagem do material orgânico. Há uma infinidade de modelos de banheiro seco de compostagem, que varia entre o mais simples ao mais elaborado. Basicamente, pode-se considerar que há dois tipos principais de banheiro seco de compostagem: o vertical e o horizontal (JENKINS, 2005).

O uso de água da chuva entrou em vigor no Brasil em 2007, possibilitando segurança na aplicação da solução ao mercado de arquitetura e construção civil com a vigência da ABNT

28 Informação divulgada pelo Ministério de Minas e Energia: <http://www.mme.gov.br/todas-as-noticias//asset_publisher/pdAS9IcdBICN/content/governo-federal-inaugura-uma-das-maiores-plantas-de-biogas-nomundo-para-geracao-de-energia-eletrica-sustentavel>. Acesso em: 01 Nov. 2020.

29 BRASIL. Resolução n 08/2015 (2015). Ministério de Minas e Energia. Agência Nacional do Petróleo, Gás Natural e Biocombustíveis. Disponível em: <http://legislacao.anp.gov.br/?path=legislacao-anp/resolanp/2015/janeiro\&item=ranp-8--2015>. Acesso em: 01 Nov. 2020.

30 BRASIL. Resolução n 685/2017 (2017). Ministério de Minas e Energia. Agência Nacional do Petróleo, Gás Natural e Biocombustíveis. Disponível em: <http://legislacao.anp.gov.br/?path=legislacao-anp/resolanp/2017/junho\&item=ranp-685--2017>. Acesso em: 01 Nov. 2020.

31 JENKINS, Joseph C. The Humanure Handbook. A Guide to Composting Human Manure. Third Edition.. USA: Chelsea Green, 2005. 


\section{ASPECTOS TECNOLÓGICOS DA “TINY HOUSE” E SUA REGULAMENTAÇÃO NO BRASIL FRENTE À SUSTENTABILIDADE SOCIOAMBIENTAL}

NBR $15527^{32}$, norma que rege o sistema de tratamento e aproveitamento de água pluvial no país. A aplicação de tecnologia do armazenamento e aproveitamento de água da chuva em "tiny house” combinada com a reutilização responsável (irrigação, lavagens em geral, entre outras finalidades não potáveis) permite que os benefícios ambientais ultrapassem o intuito de economia da água potável tratada no modo convencional.

A normalização da Associação Brasileira de Normas Técnicas ${ }^{33}$ do catálogo da ABNT NBR 15527 foi elaborado pela Comissão de Estudo Especial temporária de Aproveitamento de Água de Chuva (ABNT/CEET-00.001.77) em dois projetos. O primeiro projeto circulou em consulta nacional conforme Edital $n^{\circ}$ 01, de 31.01.2007, com o número de Projeto 00:001.77001. E o segundo projeto circulou em consulta nacional conforme Edital $n^{\circ}$ 05, de 23.04.2007 a 21.05.2007, com o número de segundo projeto 00:001.77-001 (ABNT, 2007).

O estilo de vida minimalista ${ }^{34}$ em tiny house implica na necessidade de adaptação em novo modo de viver, obviamente, inclui a otimização dos espaços do lar, exploração de estratégias que integrem os ambientes e os móveis multifuncionais à vida diária do morador. Móveis, sofás-camas e mesas que aparecem e desaparecem em bancadas, painéis embutidos, escadas que se transformam em gaveteiros, paredes que escondem livreiros e armários diversos, são algumas alternativas utilizadas para o aproveitamento dos espaços reduzidos.

Considerando os eletrodomésticos e eletroeletrônicos básicos das residências brasileiras $^{35}$ (IBGE, 2020) que melhor se adequam aos espaços pequenos como a tiny house, a restrição ao consumismo desnecessário no estilo minimalista (FERREIRA, 2010), induz o critério de aquisição, optando-se por equipamentos tecnológicos sustentáveis que permitam suprir a necessidade, mas também proporcionem conforto e a qualidade de vida do morador.

\section{RELEVÂNCIA SOCIAL DA TINY HOUSE}

Um número cada vez maior de famílias, que vivem com renda abaixo de três salários mínimos ${ }^{36}$, submetem-se às formas adaptadas de habitação e/ou exercem construções

32 ABNT. ABNT NBR 15527 (2007). Aproveitamento de água da chuva. Disponível em: <https://www.abntcatalogo.com.br/curs.aspx?ID=34>. Acesso em: 01 Nov. 2020.

33 ABNT. Associação Brasileira de Normas Técnicas Normalização. Catálogos. Disponível em: < http://www.abnt.org.br/normalizacao/abnt-catalogo>. Acesso em: 01 Nov. 2020.

34 FERreirA, Aurélio Buarque de Holanda. Dicionário Aurélio da Língua Portuguesa. Minimalista. $5^{\mathrm{a}}$ Edição. Curitiba: Positivo, 2010.

35 IBGE. Habitação. Instituto Brasileiro de Geografia e Estatística (2020). Disponível em: <https://brasilemsintese.ibge.gov.br/habitacao.html>. Acesso em: 01 Nov. 2020.

36 GONZALES, Suely Franco Netto. A Produção da Moradia como Política Pública: Construindo um novo paradigma. Série Memória Acadêmica. Volume 2. Brasília: Simplíssimo Livros, 2020, p.6. 
irregulares em dissonância com a legislação vigente que regulamenta o tema. Quando o domínio da renda se direciona para fins de moradia, a população se obriga a migrar para áreas periféricas, proporcionais às suas finanças, normalmente bem distantes dos centros urbanos (GONZALEZ, 2020).

A tiny house representa uma moradia sustentável ${ }^{37}$ que atende o seu papel social em um método de contenção do consumismo exacerbado (CARRAS, 2018), além da possibilidade de adoção da inovação e do aprimoramento da tecnologia ambiental, voltado ao conceito minimalista de habitação, visando o desenvolvimento sustentável e a preservação do meio ambiente para a atual geração e em prol das futuras gerações ${ }^{38}$ (GORE, 2006).

A relação fundamental entre a civilização e o sistema ecológico do planeta foi transformada, total e radicalmente, por causa da poderosa convergência de três fatores: a explosão populacional, a revolução da inovação científica e tecnológica e a crise climática, resultado do aquecimento global, tornado a humanidade uma força da natureza ${ }^{39}$ (GORE, 2006).

Segundo os dados do Instituto Brasileiro de Geografia e Estatística, a população brasileira já atinge aproximadamente de 212.500 .000 pessoas $^{40}$. As projeções da população do Brasil e das Unidades da Federação investigadas pelo Instituto Brasileiro de Geografia e Estatística (IBGE, 2020), demonstram que os índices de mortalidade e natalidade têm diminuído rapidamente, gerando o rápido crescimento populacional o que, por consequência, resulta em maior demanda dos escassos recursos naturais.

Os avanços científicos e as novas tecnologias são essencialmente importantes para a sobrevivência da civilização; todavia mostram-se insuficientes para a preservação do meio ambiente. Mantendo-se a degradação desenfreada; aliada aos maus hábitos já instalados no estilo de vida convencional; o sistema ecológico é ferido e as consequências são inevitáveis, porém previsíveis.

O instinto humano de buscar a melhoria na sua posição material está profundamente enraizado ao passado evolutivo: o domínio sobre os recursos, especialmente alimentos e abrigo,

37 CARRAS, Megan Elizabeth. “Tiny House, Big Impact?”: An investigation into the 'rise’ of the Tiny Home Lifestyle (THL) in the United States. Reino Unido (Escócia): University of St Andrews, 2018.

38 GORE, Albert. Uma Verdade Inconveniente: O que devemos saber (e fazer) sobre o aquecimento global. Tradução: Isa Mara Lando. Barueri: Manole, 2006.

39 GORE, Albert. Uma Verdade Inconveniente: O que devemos saber (e fazer) sobre o aquecimento global. Tradução: Isa Mara Lando. Barueri: Manole, 2006.

40 IBGE. População. Instituto Brasileiro de Geografia e Estatística (2020). Disponível em: $<$ https://www.ibge.gov.br/apps/populacao/projecao/index.html?utm_source=portal\&utm_medium=popcloc k>. Acesso em: 01 Nov. 2020. 


\section{ASPECTOS TECNOLÓGICOS DA “TINY HOUSE” E SUA REGULAMENTAÇÃO NO BRASIL FRENTE À SUSTENTABILIDADE SOCIOAMBIENTAL}

tornavam os humanos primitivos mais aptos a se reproduzirem. O desejo de adquirir renda e riqueza, adquirindo bens materiais é o que motiva os indivíduos a trabalharem, economizarem, inventarem e investirem ${ }^{41}$ (PORTES, 2017).

A verdade sobre o aquecimento global é especialmente inconveniente e desagradável para algumas pessoas e empresas muito poderosas, que ganham enormes quantias de dinheiro com atividades que, elas sabem muito bem, terão de mudar radicalmente para que seja possível continuar a se viver neste planeta. (...)

Não podemos mais nos dar ao luxo da inação; e, francamente, não há desculpa para não fazer nada. Todos nós desejamos a mesma coisa: que nossos filhos e as gerações posteriores possam herdar um planeta limpo e belo, capaz de sustentar uma civilização humana saudável. Esse objetivo deveria transcender a política. (GORE, 2006)

Sim, a ciência continua sempre evoluindo; mas já existem dados suficientes e já foram causados prejuízos suficientes, para sabermos, sem sombra de dúvida, que estamos em perigo. Não se trata de um debate ideológico com dois lados, a favor e contra. Existe apenas um planeta Terra, e todos nós que vivemos nele compartilhamos um futuro em comum. No momento estamos diante de uma emergência planetária, e é hora de agir, não dar ouvidos a falsas controvérsias que só visam causar a paralisia política $^{42}$. (GORE, 2006).

Neste sentido, é fundamental a implementação de políticas públicas no Brasil, validando a norma constitucional brasileira que garante o direito à propriedade $\mathrm{e}^{43}$, o direito à moradia ${ }^{44} \mathrm{e}$ ao meio ambiente ecologicamente equilibrado ${ }^{45}$, de modo que a tiny house torne-se uma opção de moradia sustentável, com uso responsável dos recursos naturais (água, gás e energia), esgoto sanitário, coleta de lixo e consumo sustentável, objetivando a conscientização e o cumprimento da sua função social ${ }^{46}$, essencial à sadia qualidade de vida para toda humanidade.

\section{ESTUDO DE CASO: CONDOMÍNIO EM TINY HOUSE (CURITIBA/PR)}

Em 2018, um empresário iniciou a construção de empreendimento do condomínio em área nobre do Município de Curitiba, Estado do Paraná, com o objetivo de instalar de forma inédita, em mais de $700 \mathrm{~m}^{2}$ até vinte e cinco unidades de tiny house fixa e/ou móvel, disponíveis

41 PORTES, Jonathan. 50 Ideias de Capitalismo que Você Precisa Conhecer. Tradução: Helena Londres. $1^{\text {a }}$ Edição. São Paulo: Planeta, 2017.

42 GORE, Albert. Uma Verdade Inconveniente: O que devemos saber (e fazer) sobre o aquecimento global. Tradução: Isa Mara Lando. Barueri: Manole, 2006.

43 BRASIL. Constituição da República Federativa do Brasil (1988). Artigo 5², Inciso XXII. Disponível em: <http://www.planalto.gov.br/ccivil_03/constituicao/constituicao.htm>. Acesso em: 01 Nov. 2020.

44 BRASIL. Constituição da República Federativa do Brasil (1988). Artigo 6º Disponível em: <http://www.planalto.gov.br/ccivil_03/constituicao/constituicao.htm>. Acesso em: 01 Nov. 2020.

45 BRASIL. Constituição da República Federativa do Brasil (1988). Artigo 225. Disponível em: <http://www.planalto.gov.br/ccivil_03/constituicao/constituicao.htm>. Acesso em: 01 Nov. 2020.

46 BRASIL. Constituição da República Federativa do Brasil (1988). Artigo 5º Inciso XXIII. Disponível em: <http://www.planalto.gov.br/ccivil_03/constituicao/constituicao.htm>. Acesso em: 01 Nov. 2020. 
no modelo plus ( $25 \mathrm{~m}^{2}$ por $\left.\mathrm{R} \$ 40 \mathrm{mil}\right)$, small (12 $\mathrm{m}^{2}$ por $\left.\mathrm{R} \$ 25 \mathrm{mil}\right)$ ou travel (9 $\mathrm{m}^{2}$ por $\mathrm{R} \$ 20$ $\operatorname{mil})^{47}$.

O preço da taxa de condomínio pela hospedagem da tiny house no respectivo local foi calculado em R \$ 190,00 (cento e noventa reais), incluindo o direito de uso da churrasqueira, piscina, deque, lavanderia compartilhada e bicicletário, excluindo apenas as contas de água e luz, que seriam cobradas individualmente.

O empresário, idealizador da obra, inconformado com os altos valores dos condomínios convencionais no Brasil, vislumbrou na tiny house uma opção de moradia viável e confortável para os brasileiros, assim como, um nicho de mercado lucrativo, ainda não explorado no Brasil.

Eu morava em um apartamento em que a taxa de condomínio era de R\$ 600. Um valor inviável para um condomínio que não tinha nada. Percebi que tinha que ter algo financeiramente mais viável e confortável”, relembra. A partir disso, descobriu as tiny houses e fez adaptações para o modelo de vida brasileiro. “Aqui não dá para ser como nos Estados Unidos, em que a pessoa compra uma tiny house, para em parques públicos e mora. Aqui tem que ser em condomínios”, relata. As tiny houses são levantadas com pinus autoclavado e vêm com todos os itens de acabamento, sendo bem fáceis de montar e desmontar. “A ideia é que no futuro, quando você mudar de emprego, por exemplo, em vez de gastar muito tempo no deslocamento casa-trabalho, você possa sair do seu condomínio e ir para outro mais próximo do seu novo emprego. Dessa forma você ganha em qualidade de vida”, sentencia o empresário, que já aderiu ao fenômeno das tiny houses. ${ }^{48}$

Importante salientar que no mesmo bairro do local escolhido para construção do condomínio de tiny house, com vista ao Parque Barigui, no Município de Curitiba/PR, iniciaram outros empreendimentos convencionais de alto padrão, com arquitetura e design moderno e metragens de apartamentos que variam entre 85 m², $95 \mathrm{~m}^{2}$ e $130 \mathrm{~m}^{2}$, além das coberturas, com 167 m² e 185 m², construções de alto investimento econômico.

O Instituto de Pesquisa e Planejamento Urbano de Curitiba (IPPUC) restringe a mobilidade das moradias em tiny house sobre rodas, por considerar a falta de tipificação especial para permissão em determinados zoneamentos do Município de Curitiba, em dissonância com os parâmetros da Lei n 9.503/1997 ${ }^{49}$ (BRASIL, 1997) do Código de Trânsito Brasileiro e em obediência às diretrizes da Política Nacional de Trânsito, Decreto $n^{\circ}$

47 Reprodução da informação divulgada por Luan Galani, em 11.04.2018. Disponível em: $<$ https://www.gazetadopovo.com.br/haus/imoveis/curitiba-ganha-primeiro-condominio-de-tiny-houses-aolado-do-parque-barigui/>. Acesso em: 01 Nov. 2020.

48 Reprodução da informação divulgada por Luan Galani, em 11.04.2018. Disponível em: $<$ https://www.gazetadopovo.com.br/haus/imoveis/curitiba-ganha-primeiro-condominio-de-tiny-houses-aolado-do-parque-barigui/>. Acesso em: 01 Nov. 2020.

49 BRASIL. Código de Trânsito Brasileiro (1997). Disponível em: <http://www.planalto.gov.br/ccivil_03/leis/L9503Compilado.htm>. Acesso em: 01 Nov. 2020. 
4.711/2003 ${ }^{50}$ (BRASIL, 2003) sobre a coordenação do Sistema Nacional de Trânsito e Resolução n 743/2018 ${ }^{51}$ (BRASIL, 2018) do Conselho Nacional de Trânsito, que estabelecem os limites e requisitos permissivos.

A Prefeitura do Município de Curitiba, assim como todos os Municípios das Unidades Federativas do Brasil, delimitam as dimensões mínimas que uma residência deve ter para abrigar uma família. As medidas estabelecidas para o Município de Curitiba, Estado do Paraná, estão listadas no anexo III da Portaria ${ }^{\circ}$ 80/2013 52 (CURITIBA, 2013), em consonância com os parâmetros da norma municipal da Lei de Zoneamento e Uso do Solo ${ }^{53}$ (IPPUC, 2019 e IPPUC, 2020).

Após a divulgação do condomínio de tiny hous”, o empresário foi multado ${ }^{54}$ e as obras imediatamente paralisadas, a pedido da Procuradoria Geral do Município de Curitiba, diante da ausência do alvará de construção que deveria ter sido emitida pela Secretaria Municipal de Urbanismo de Curitiba.

Ainda que o projeto arquitetônico tivesse sido protocolado na Prefeitura do Município local, o alvará de construção não teria sido expedido pelo secretário de Urbanismo de Curitiba, pois a Lei de Zoneamento e Uso do Solo (IPPUC, 2019 e IPPUC, 2020) autoriza a construção de apenas uma habitação a cada fração de $600 \mathrm{~m}^{2}$ de terreno, e no caso concreto, o projeto arquitetônico do condomínio de tiny house previa a proporção de vinte e cinco habitações em um terreno com metragem total aproximada de $700 \mathrm{~m}^{2}$.

\section{CONSIDERAÇÕES FINAIS}

O estilo de vida minimalista é uma opção sustentável de moradia no Brasil que propõe a mudança dos maus hábitos no uso dos recursos naturais (água, gás, energia, esgoto sanitário, coleta de lixo, entre outros), eliminando o consumismo excessivo, propondo soluções para a preservação do meio ambiente ecologicamente equilibrado com uso de inovação e tecnologia,

50 BRASIL. Sistema Nacional de Trânsito (2003). Disponível em: <http://www.planalto.gov.br/ccivil_03/decreto/2003/D4711.htm>. Acesso em: 01 Nov. 2020.

51 BRASIL. Resolução $\mathbf{n}^{\circ} \mathbf{7 4 3 / 2 0 1 8}$ do Conselho Nacional de Trânsito (2018). Disponível em: <https://www.in.gov.br/materia/-/asset_publisher/Kujrw0TZC2Mb/content/id/51523850/do1-2018-11-23resolucao-n-743-de-12-de-novembro-de-2018-51523534>. Acesso em: 01 Nov. 2020.

52 CURITIBA. Portaria $\mathbf{n}^{\circ} \mathbf{8 0 / 2 0 1 3}$ (2013). Secretaria Municipal de Urbanismo. Disponível em: <https://www.curitiba.pr.gov.br/conteudo/legislacao-smu/211>. Acesso em: 01 Nov. 2020.

53 IPUCC. Lei $\mathbf{n}^{\circ}$ 15.511/2019 (2019) e Lei ${ }^{\circ}$ 15.661/2020 (2020). Instituto de Pesquisa e Planejamento Urbano de Curitiba. Disponível em: < https://ippuc.org.br/leizoneamento.php>. Acesso em: 01 Nov. 2020.

54 Reprodução da informação divulgada por Vivian Faria, em 25.07.2018. Disponível em: $<$ https://www.gazetadopovo.com.br/haus/urbanismo/legislacao-atrasada-inercia-municipios-curitibaemperram-desenvolvimento-das-tiny-houses-no-brasil/>. Acesso em: 01 Nov. 2020. 
priorizando a aquisição e uso apenas do que é minimamente essencial para a qualidade de vida do brasileiro.

A legislação brasileira vigente prevê a tiny house sobre rodas, limitando-se a aquisição e transformação do veículo, nos termos da Lei n 9.503/1997 (BRASIL, 1997) do Código de Trânsito Brasileiro e em obediência às diretrizes da Política Nacional de Trânsito, Decreto nº 4.711/2003 (BRASIL, 2003) sobre a coordenação do Sistema Nacional de Trânsito e Resolução nº 743/2018 (BRASIL, 2018) do Conselho Nacional de Trânsito.

Em todo o Brasil, o imóvel deve respeitar os mesmos parâmetros da Lei de Zoneamento e Uso do Solo (afastamento de divisas, calçadas, acesso a pedestres e veículos, tamanho de estacionamento, entre outros) de uma moradia com tamanho convencional, ainda que possua características de tiny house com fundação fixa, determinação da Lei n 4.591/1964 (BRASIL, 1964), Lei $n^{\circ}$ 6.015/1973 (BRASIL, 1973), Lei $n^{\circ}$ 6.766/1979 (BRASIL, 1979), Lei $n^{\circ}$ 7.433/1985 (BRASIL, 1985) e Decreto n 93.240/1986 (BRASIL, 1986).

A tiny house com fundação fixa é de difícil concretização, especialmente nos grandes centros urbanos, quando aplicados os mesmos padrões legislativos de exigências das habitações convencionais. O investimento da tiny house torna-se elevado, além de afastar a proposta principal do minimalismo se cumpridas às metragens mínimas preestabelecidas em Lei. Neste sentido, encontra-se a necessidade de adaptação frente às normas, a fim de permitir que o brasileiro possa exercer o seu direito de propriedade, direito à moradia e direito de viver em ambiente ecologicamente equilibrado, previsão da Constituição Federal (BRASIL, 1988).

Configura-se em um novo paradigma de moradia no Brasil, diante da inexistência de legislação específica que regulamente a moradia em tiny house. Nos termos da atual legislação em vigor, a aquisição e a construção desta nova modalidade de habitação se depara na dificuldade de exercício do direito de escolha pelo estilo de vida minimalista, adstrito à prévia verificação e ausência de impedimento da Lei de Zoneamento e Uso do Solo local.

As políticas públicas devem regulamentar e incentivar a aquisição de modo de vida minimalista, com uso de tecnologias sustentáveis com implementação de tiny house, para que o imóvel cumpra a sua função social e preservação do meio ambiente, delineando novos hábitos de consumo responsável, em conjunto com as práticas de tecnologia sustentável.

Transformar o combate dos comportamentos nocivos como um catalizador de mudanças positivas, seja através de políticas públicas que possibilitem uma regulamentação da opção de moradia em tiny house ou por incentivo da implementação de bons hábitos, consumo responsável e sustentável, como grande desafio para adequação às normas do ordenamento 
jurídico brasileiro, além de fator preeminente ao combater da crise climática e do aquecimento global.

\section{REFERÊNCIAS}

ABIKO, Alex Kenya. Introdução à gestão habitacional. São Paulo, EPUSP. Texto técnico da Escola Politécnica da USP, Departamento de Engenharia de Construção Civil, TT/PCC/12. 1995.

ABNT, Associação Brasileira de Normas Técnicas. Normalização. Catálogos. Disponível em: < http://www.abnt.org.br/normalizacao/abnt-catalogo>. Acesso em: 01 Nov. 2020.

ABNT. ABNT NBR 15527 (2007). Aproveitamento de água da chuva. Disponível em: <https://www.abntcatalogo.com.br/curs.aspx?ID=34>. Acesso em: 01 Nov. 2020.

AGENCIA EUROPEIA DO AMBIENTE. Sobre tecnologia ambiental. Disponível em: <https://www.eea.europa.eu/pt/themes/technology/about>. Acesso em: 01 Dez. 2020.

BNDES. Banco Nacional do Desenvolvimento (2018). Disponível em:

$<$ https:/www.bndes.gov.br/wps/portal/site/home/conhecimento/noticias/noticia/energiasolar>. Acesso em: 01 Nov. 2020.

BRASIL. Resolução n ${ }^{\circ}$ 743/2018 do Conselho Nacional de Trânsito (2018). Disponível em: < https://www.in.gov.br/materia/-

/asset_publisher/Kujrw0TZC2Mb/content/id/51523850/do1-2018-11-23-resolucao-n-743-de12-de-novembro-de-2018-51523534>. Acesso em: 01 Nov. 2020.

BRASIL. Acordo de Paris (2016). Ministério do Meio Ambiente. Disponível em: $<$ https://www.mma.gov.br/clima/convencao-das-nacoes-unidas/acordo-de-paris.html >. Acesso em: 01 Nov. 2020.

BRASIL. Código de Trânsito Brasileiro (1997). Disponível em: <http://www.planalto.gov.br/ccivil_03/leis/L9503Compilado.htm>. Acesso em: 01 Nov. 2020.

BRASIL. Condomínio em edificações e as incorporações imobiliárias (1964). Disponível em: <http://www.planalto.gov.br/ccivil_03/leis/14591.htm>. Acesso em: 01 Nov. 2020.

BRASIL. Constituição da República Federativa do Brasil (1988). Artigo 5², Inciso XXII. Disponível em: <http://www.planalto.gov.br/ccivil_03/constituicao/constituicao.htm>. Acesso em: 01 Nov. 2020.

BRASIL. Constituição da República Federativa do Brasil (1988). Artigo 6º . Disponível em: <http://www.planalto.gov.br/ccivil_03/constituicao/constituicao.htm>. Acesso em: 01 Nov. 2020.

BRASIL. Constituição da República Federativa do Brasil (1988). Artigo 225. Disponível em: <http://www.planalto.gov.br/ccivil_03/constituicao/constituicao.htm>. Acesso em: 01 Nov. 2020. 
BRASIL. Constituição da República Federativa do Brasil (1988). Artigo 5º Inciso XXIII. Disponível em: <http://www.planalto.gov.br/ccivil_03/constituicao/constituicao.htm>. Acesso em: 01 Nov. 2020.

BRASIL. Lavratura de Escrituras Públicas (1985). Disponível em: < http://www.planalto.gov.br/ccivil_03/leis/17433.htm>. Acesso em 01 Nov. 2020.

BRASIL. Parcelamento do Solo Urbano (1979). Disponível em: < http://www.planalto.gov.br/ccivil_03/LEIS/L6766.htm>. Acesso em: 01 Nov. 2020.

BRASIL. Registros Públicos (1973). Disponível em: < http://www.planalto.gov.br/CCivil_03/leis/L6015consolidado.htm>. Acesso em: 01 Nov. 2020.

BRASIL. Requisitos para Lavraturas de Escrituras Públicas (1986). Disponível em: $<$ http://www.planalto.gov.br/ccivil_03/decreto/Antigos/D93240.htm>. Acesso em: 01 Nov. 2020.

BRASIL. Resolução n 08/2015 (2015). Ministério de Minas e Energia. Agência Nacional do Petróleo, Gás Natural e Biocombustíveis. Disponível em: < http://legislacao.anp.gov.br/?path=legislacao-anp/resol-anp/2015/janeiro\&item=ranp-8-2015>. Acesso em: 01 Nov. 2020.

BRASIL. Resolução n 685/2017 (2017). Ministério de Minas e Energia. Agência Nacional do Petróleo, Gás Natural e Biocombustíveis. Disponível em:<

http://legislacao.anp.gov.br/?path=legislacao-anp/resol-anp/2017/junho\&item=ranp-685-2017>. Acesso em: 01 Nov. 2020.

BRASIL. Sistema Nacional de Trânsito (2003). Disponível em:

<http://www.planalto.gov.br/ccivil_03/decreto/2003/D4711.htm>. Acesso em: 01 Nov. 2020.

CAMBRIGDE DICTIONARY. House. Disponível em: <

https://dictionary.cambridge.org/pt/dicionario/ingles-portugues/house>. Acesso em: 01 Nov. 2020.

CAMBRIGDE DICTIONARY. Tiny. Disponível em: $<$ https://dictionary.cambridge.org/pt/dicionario/ingles-portugues/tiny>. Acesso em: 01 Nov. 2020.

CARRAS, Megan Elizabeth. “Tiny House, Big Impact?”: An investigation into the 'rise' of the Tiny Home Lifestyle (THL) in the United States. Reino Unido (Escócia): University of St Andrews, 2018.

CURITIBA. Portaria n 80/2013 (2013). Secretaria Municipal de Urbanismo. Disponível em: <https://www.curitiba.pr.gov.br/conteudo/legislacao-smu/211>. Acesso em: 01 Nov. 2020.

ENGELS, Friedrich. A Questão da Habitação. São João del Rei: Estudos Vermelhos, 2013.

ERREIRA, Aurélio Buarque de Holanda. Dicionário Aurélio da Língua Portuguesa.

Minimalista. 5a Edição. Curitiba: Positivo, 2010. 
GONZALES, Suely Franco Netto. A Produção da Moradia como Política Pública: Construindo um novo paradigma. Série Memória Acadêmica. Volume 2. Brasília: Simplíssimo Livros, 2020.

GORE, Albert. Uma Verdade Inconveniente: O que devemos saber (e fazer) sobre o aquecimento global. Tradução: Isa Mara Lando. Barueri: Manole, 2006.

HOLMES, Stephen. SUNSTEIN, Cass R. O Custo dos Direitos: Porque a liberdade depende dos impostos. Tradução: Marcelo Brandão Cipolla. $1^{\text {a }}$ Edição. São Paulo: WMF Martins Fontes, 2019, p.93-94.

IBGE. Habitação. Instituto Brasileiro de Geografia e Estatística (2020). Disponível em: <https://brasilemsintese.ibge.gov.br/habitacao.html>. Acesso em: 01 Nov. 2020.

IBGE. População. Instituto Brasileiro de Geografia e Estatística (2020). Disponível em: $<$ https://www.ibge.gov.br/apps/populacao/projecao/index.html?utm_source=portal\&utm_ medium=popclock> . Acesso em: 01 Nov. 2020.

IPUCC. Lei $\mathbf{n}^{\circ}$ 15.511/2019 (2019) e Lei $n^{\circ}$ 15.661/2020 (2020). Instituto de Pesquisa e Planejamento Urbano de Curitiba. Disponível em: < https://ippuc.org.br/leizoneamento.php>. Acesso em: 01 Nov. 2020.

JENKINS, Joseph C. The Humanure Handbook. A Guide to Composting Human Manure. Third Edition.. USA: Chelsea Green, 2005.

ONU. O impacto da tecnologia nos direitos humanos: estudos de caso globais, United Nations University Press, 1993.

PORTES, Jonathan. 50 Ideias de Capitalismo que Você Precisa Conhecer. Tradução: Helena Londres. 1ª Edição. São Paulo: Planeta, 2017.

RISÉRIO, Antonio. A Casa no Brasil. $1^{a}$ Edição. Rio de Janeiro: Topbooks, 2019, p.328329.

Data de submissão: 02/10/2020

Data de aprovação: 16/10/2020

Data de publicação: 31/12/2020

Este trabalho está licenciado sob uma licença Creative Commons Attribution 4.0 International License. 